\title{
GENDER DIFFERENCES IN EMOTIONAL INTELLIGENCE AMONG FIRST YEAR MEDICAL STUDENTS
}

\author{
Kavana G. Venkatappa, Smrithi Shetty. C, Sparshadeep E. M, Shibin Girish Parakandy, S. K. Das
}

1. Assistant Professor, Department of Physiology, A. J. Institute of Medical Sciences, Mangalore, Karnataka.

2. Assistant Professor, Department of Physiology, A. J. Institute of Medical Sciences, Mangalore, Karnataka.

3. Assistant Professor, Department of Pharmacology, A. J. Institute of Medical Sciences, Mangalore, Karnataka.

4. Assistant Professor, Department of Ophthalmology, Yenepoya Medical College, Mangalore, Karnataka.

5. Professor \& Head, Department of Physiology, A. J. Institute of Medical Sciences, Mangalore, Karnataka.

\section{CORRESPONDING ADDRESS:}

Dr. Kavana G. Venkatappa

D/O Venkatappa B, AAO

No.7, 1st floor, Police Officers Quarters

Beside Chamrajpet police station

Chamrajpet, Bangalore 560018, Karnataka, India

Email: dr.kavana.gv@gmail.com

Phone: 00919591018000,00919663328880

\begin{abstract}
BACKGROUND: Emotions are our feelings; if properly used are essential tools for successful and fulfilling life. Emotional Intelligence (EI) is defined as "the composite set of capabilities that enable a person to manage himself / herself and others". Six important facets of Emotional Intelligence are: self-awareness, self-confidence, self-control, empathy, motivation and social-competency. The stereotype of women being the more "emotional" sex survives to this day and women tend to have an edge over men when it comes to basic skills for a happy and successful life. AIMS: The objective of the study was to determine the gender differences in Emotional Intelligence among first year medical students. SETTINGS \& STUDY DESIGN: The study included 150 first year medical students. Informed consent and ethical clearance was obtained. METHODS: Emotional Intelligence was assessed using emotional quotient selfassessment checklist to which subjects responded on five-point Likert scale. RESULTS: The mean scores of Emotional Intelligence in males and females were compared using unpaired students t-test. Emotional Intelligence was significantly high in females $(105.34 \pm 7.73)$ compared to males $(102.06 \pm 8.87)(p=0.02)$. CONCLUSION: The reason might be due to the fact that women tend to be more emotionally expressive than men and understand emotions better. In addition, some evidence exists that certain areas of the brain dedicated to processing emotions could be larger in women than in men. Hence the present study may provide a better insight into individual's emotional development and also psychoeducational intervention on individual's emotional balance which might indirectly influence their success in career and family life.
\end{abstract}

KEY WORDS: Emotional Intelligence, First Year Medical Students, Gender Difference.

INTRODUCTION: Emotions are our feelings; if properly used are essential tools for successful and fulfilling life. But if emotions are out of control, it can result in disaster. In day-to-day life, they affect our relations with other people, our self-identity and our ability to complete a task. The famous psychologist E.L. Thorndike, through his concept of social intelligence, laid down a solid foundation of the essence of emotional intelligence (EI) in 1920.In modern times, the term EI was popularized by Goleman (1). 
With the dawn of 21st century, the human mind added a new dimension which is now being held responsible more for success than intelligence. This is termed as Emotional Intelligence and is measured as EQ (Emotional Quotient). Emotional intelligence is defined as "the composite set of capabilities that enable a person to manage himself/ herself and others" (2).

\section{COMPONENTS OF EMOTIONAL INTELLIGENCE: (3)}

Six important facets of Emotional intelligence are: self-awareness, self-confidence, selfcontrol, empathy, motivation and social-competency.

Self-awareness refers to an awareness of ourselves on many different levels: our body and our physical reactions; our emotions, preferences, and intentions; our goals and values; and our knowledge about how we come across to others. The more self-awareness we have, the more easily we can adjust our responses to others, and the more mutually satisfying our interactions and transactions.

Self-confidence is a positive and balanced attitude having to do with the Self dimension. It consists of a basic belief that we can do what is needed to produce the desired outcome. When obstacles occur, a person with a confident attitude continues to work to overcome the barriers. Overcoming barriers and giving ourselves credit for what we have achieved are important ways to build self-confidence.

Self-control is based on our having a positive self-attitude and enough self-knowledge to make the right decision about what to do with an emotion. The thinking brain can make decisions about emotions. Not all of them need to be expressed, but they also don't need to be hidden or denied. Emotionally intelligent people display feelings if they are relevant, and deal positively with emotions they can't show.

The first step toward skillful social behaviour is social knowledge or awareness. Such awareness or ability to tune in to others and feel what they are feeling is called empathy. Without empathy, we have difficulty sustaining relationships. People with high EQ have a number of strong relationships in all areas of their lives.

Emotion is the foundation for creativity, passion, optimism, drive, and transformation. Motivation is a synonym for enthusiasm, initiative, and persistence. A positive attitude in the social dimension is motivation, one of the key facets of Emotional Intelligence and of leadership. Appropriate behavior in the social dimension leads to Social Competency. To develop such social skills, we must focus on other people, rather than on what we are experiencing or want to say. If we are preoccupied, we will not be able to pay close enough attention to the other person in order to know how to respond appropriately.

It is believed that emotional intelligence plays a very important role in leadership, work life and career development. Intelligence Quotient predicts only about 20 percent of career successes, which leave the remaining 80 percent to other factors such as emotional intelligence (4).

EMOTIONAL INTELLIGENCE AND GENDER: The stereotype of women being the more "emotional" sex survives to this day and women tend to have an edge over men when it comes to basic skills for a happy and successful life (5).

Also women differ from men. For instance, if the other person is upset, or the emotions are disturbing, women's brains tend to stay with those feelings. But men's brains do something else: they sense the feelings for a moment, then tune out of the emotions and switch to other 
brain areas that try to solve the problem that's creating the disturbance. Thus women's complaint that men are tuned out emotionally, and men's that women are too emotional-it's a brain difference (6).

Combining emotions with cognition would lead to a better day-to-day adaptation and conflict resolution by using not only our intellectual capacities but also the additional information provided by our moods (5).

With this background the present preliminary study has been undertaken to determine the gender differences in EI among first year medical students.

MATERIAL AND METHODS: This preliminary study was conducted in Department of Physiology, A.J.I.M.S, Mangalore with 150 first year medical students (89 females \& 61 males) after obtaining their informed and written consent for the study. Ethical clearance was obtained from Institutional Ethical Clearance Committee. It is a cross-sectional, single interview study. Subjects included did not have any diagnosed medical or psychiatric illness as per history. EI was assessed using Emotional Quotient Self-Assessment Checklist (Table 1) devised by Sterrett (3). The questionnaire also included a section for age, gender and identifying information (College ID number).

Emotional Quotient Self-Assessment Checklist: It consists of 30 statements, five each for the areas for self-awareness, self-confidence, self-control, empathy, motivation and socialcompetency. This is a five- point Likert rating scale, ranging from 1 to 5 ; total score on each of 6 facets range from 5 to 25 and a cut -off value for good EI is 20 in each domain, the score below which needs improvement in the respective domain. Total score of EI including all the domains ranges from 30 to 180 .

Scoring the Self-Assessment Checklist (Table 1):

1. The student is asked to enter ratings for each numbered question in the category where it appears.

2. Ratings are added for each category to obtain a total for that specific facet of EQ.

QUESTION NUMBERS FOR EACH DOMAIN:

$\begin{array}{ll}\text { Self-Awareness } & : 1,7,13,19,25 \\ \text { Self-confidence } & : 2,8,14,20,26 \\ \text { Self-control } & : 3,9,15,21,27 \\ \text { Empathy } & : 4,10,16,22,28 \\ \text { Motivation } & : 5,11,17,23,29\end{array}$

Social competency : $6,12,18,24,30$

3. Total score of EI is obtained by adding the scores of all the domains of EI.

STATISTICAL ANALYSIS: The data were analysed by using SPSS version 17. Unpaired students ' $\mathrm{t}$ '-test was computed to determine the significance of difference $(\mathrm{p}<0.05)$ between males and females on Emotional Quotient Self-Assessment Checklist. Results are expressed as mean \pm standard deviation.

RESULTS: Table 2 reveals that majority of males, females and the total sample (males \& females) had good EI (63.57\%, 68.5\% \& 66.04\% respectively) and percentage with regard to EI was high in females compared to males. 
Table 3 shows differences between mean scores of males and females in their emotional intelligence. EI was significantly more in females $(105.37 \pm 7.73)$ compared to males $(102.06 \pm 8.87)$ with $p$ value of 0.02

DISCUSSION: The findings from this study among first year medical students showed significant difference in EI between males and females where in females had higher EI scores compared to males (Table 3). The obtained results are in line with the findings of previous studies $(7,8,9$, 10). They all found females to have higher emotional intelligence than that of males.

The reason for the present findings might be due to the fact that emotional intelligence primarily deals with managing and expressing one's emotions as well as social skills (10). It has been affirmed that women tend to be more emotionally expressive than men, that they understand emotions better and that they have a greater ability as regards certain interpersonal skills. Women for instance, recognize other people's emotions better, are more perceptive and have greater empathy (11). So their emotional intelligence ought to be higher than that of males. In addition, some evidence exists that certain areas of the brain dedicated to processing emotions could be larger in women than in men and that there is a difference in cerebral activity based on sex (5).

The relationship between the female sex and the emotional competencies are closely linked since childhood. Furthermore, the fact that girls develop verbal skills earlier than boys means they are more skilled at articulating their feelings and have greater expertise in the use of words. Hence, girls have more information about the emotional world and therefore speak more about emotional aspects and use more emotional terms than boys (12). All these traits help them to acquire more emotional intelligence as compared to boys.

The present study concluded that females had high EI compared to males. Understanding of this aspect may provide better insight into individual's emotional development and also psychological and educational intervention on individual's emotional balance which might indirectly influence their success in career and family life.

The limitations of the present study;

1. As this is a preliminary study, the paper was constrained in being limited to a single year's intake of students at one medical college. Further studies both in first year of their course (to establish whether this finding is strong) and in later years (to assess any effects of EI with regards to other course components and to later progress) is required.

2. Unequal distribution of sample- more female subjects.

\section{ACKNOWLEDGEMENT:}

The authors are thankful to the first year medical students who volunteered for the study.

\section{REFERENCES:}

1. Singaravelu S. Emotional Intelligence of student teachers (pre-service) at primary level in Puducherry region. J. India Assoc. of Edu. Res 2007; 19(3\&4): 49-51.

2. Goleman D. Working with Emotional Intelligence. New-York: Bantam Books; 1998.

3. Sterrett EA. The manager's pocket guide to emotional intelligence. $2^{\text {nd }}$ ed. Mumbai: Jaico Publishing House; 2004; pp 22-24. 
4. Pool CR. Up with emotional health. Educational Leadership 1997; 54: 12-14.

5. Sanchez-Nunez MT, Fernandez-Berrocal P, Montanes J, Latorre JM. Does emotional intelligence depend on gender? The socialisation of emotional competencies in men and women and its implications. Electronic Journal of Research in Educational Psychology 2008; 6(2): 455-474.

6. Goleman D. Are women more emotionally intelligent than men? 2009April 6 [cited 2012 June 7]. In: Psychology Today [Internet]. 2011 April 29-. [about 2 screens]. Available from:http://www.psychologytoday.com/blog/the-brain-and-emotional intelligence/201104/are-women-more-emotionally-intelligent-men.

7. Sutarso P. Gender differences on the emotional intelligence inventory (EQI). Dissertation Abstracts International 1999.

8. Wing E, Love GD. Elective Affinities and Uninvited Agonies: Mapping emotions with significant others Onto Health. Emotion, Social Relationships and Health Series in Affective Science. New York: Oxford University Press; 2001.

9. Singh D. Emotional Intelligence at Work: A Professional Guide. New Delhi: Sage Publications; 2002.

10. Katyal S, Aswathi E. Gender differences in emotional intelligence among adolescents of Chandigarh. J. Hum. Ecol 2005; 17(2): 153-155.

11. Tapia M, Marsh II GE. The effects of sex and grade point average on emotional intelligence. Psicothema 2006; 18: 108-111.

12. Fivush R, Brotman MA, Buckner JP, Goodman SH. Gender differences in parent-child emotion narratives. Sex Roles 2000; 42: 233-253.

Table 1: Emotional Intelligence Self-Assessment Checklist.

\begin{tabular}{ll}
\hline Name: & Date: \\
Age: & \\
Sex: Female/Male & \\
College ID number: & \\
\hline
\end{tabular}

Rate each question below on a scale of $1-5$, according to how true it is of you.

\begin{tabular}{|rrrrr|}
\hline 1 & 2 & 3 & 4 & 5 \\
virtually never & & & & virtually always \\
\hline
\end{tabular}

1) I am aware of the physical reactions (twinges, aches, sudden changes) that signal a "gut reaction."

2) I readily admit mistakes and apologize.

3) I let go of problems, anger, or hurts from the past and I can move beyond these.

4) I generally have an accurate idea of how another person perceives me during a particular interaction.

5) I have several important things in my life that I am enthusiastic about, and I let it show.

6) I can easily meet and initiate conversation with new people when I have to.

7) I take a break or use another active method of increasing energy when I sense that 
my energy level is getting low.

8) I have little trouble taking prudent risks.

9) I "open up" with people appropriately — not too much but enough so that I don't come across as cold and distant.

10) I can engage in an interaction with another and pretty well size-up that person's mood based on non-verbal signals.

11) Others usually feel inspired and encouraged after talking to me.

12) I have no trouble making presentations in front of groups or conducting meetings.

13) I take time every day for quiet reflection.

14) I take initiative and move ahead on tasks that need to be done.

15) I refrain from making up my mind on issues and expressing my opinion until I have all the facts.

16) I have a number of people I can turn to, and I ask for their help when I need it.

17) I try to find the positive in any given situation.

18) I can deal calmly, sensitively, and proactively with the emotional displays of others.

19) I can usually identify the emotion I am feeling at any given moment.

20) I am generally comfortable in new situations.

21) I neither bury my anger nor let it explode on others.

22) I can show empathy and match my feelings with those of another person in an interaction.

23) I can keep going on a big project, despite obstacles.

24) I am respected and liked by others, even when they don't agree with me.

25) I am clear about my own goals and values.

26) I express my views honestly and thoughtfully, without being pushy.

27) I am good at managing my moods, and I seldom bring negative emotions to work.

28) I focus my full attention on another person when I listen to them.

29) I believe the work I do day-to-day has meaning and value to society.

30) I can effectively persuade others to adopt my point of view without coercing them.

Table 2: Percentage distribution in males, females and total sample.

$(\mathrm{N}=150$, males $=61$, females $=89)$

\begin{tabular}{|c|c|c|c|c|}
\hline Variable & $\begin{array}{l}\text { lategory } \\
\text { (Mean score in } \\
\text { Each domain) }\end{array}$ & Males (\%) & Females (\%) & Total (\%) \\
\hline EI & $\geq 20$ (Good) & 63.57 & 68.5 & 66.04 \\
& $<20$ (Low) & 36.43 & 31.5 & 33.96 \\
\hline
\end{tabular}

EI: Emotional Intelligence

\%: Percentage 
Table 3: Mean scores of EI in males and females.

$(\mathrm{N}=150$, males $=61$, females $=89)$

\begin{tabular}{|c|c|c|c|c|c|c|}
\hline Variable & Gender & Mean & $\begin{array}{c}\text { Standard } \\
\text { Deviation }\end{array}$ & $\begin{array}{c}\text { Standard Error } \\
\text { Mean }\end{array}$ & t-value & $\begin{array}{c}\text { Sig. } \\
\text { (2-tailed) }\end{array}$ \\
\hline EI & Male & 102.06 & 8.87 & 1.136 & 2.359 & $0.02^{*}$ \\
& Female & 105.34 & 7.73 & 0.819 & & \\
\hline
\end{tabular}

* p value $<0.05$

EI: Emotional Intelligence. 